\title{
MODEL PENGEMBANGAN KAMPUS TEMATIK DALAM KAWASAN AGROTEKNO PARK
}

\author{
BambangSoemardiono', Iwan Adi Indrawan ${ }^{2}$, Nurfahmi Muchlis ${ }^{3}$ \\ 1,2,3 Departemen Arsitektur, FADP, Institut Teknologi Sepuluh Nopember (ITS) Surabaya \\ Jl Raya ITS, Keputih, Kota Surabaya \\ *Email:bbsoem@arch.it.ac.id; bamsoem03@yahoo.com
}

\begin{abstract}
ABSTRAK
The Agro Techno Park area in North Gresik is a proposal developed by the local government with master plan design concepts with a theme that combines industry and campus based on education and research (Erica Campus). With strong potential supported by infrastructure plans for the development of north Gresik, this area has the potential to be developed. Research problems that arise are aspects of what aspects need to be considered in structuring these thematic clusters and how the criteria that help strengthen campus development planning concepts in the long term. Hanyang University is one example of the Erica campus cluster in south Korea that applies new standards and is recognized as a school that actively collaborates with industry. This cluster must have a strong and specific peculiarity because it is in the agro-industrial region so that in its footprint other than the mass, circulation and open space. There are special needs that need to be studied in depth so that the concept of merging is achieved to develop conceptual directives in the form of thematic campus development models
\end{abstract}

Keywords: agro techno park, erica campus, north Gresik

\section{PENDAHULUAN}

Dewasa ini perkembangan infrastruktur didalam dunia pendidikan semakin dibutuhkan dalam koridor perencanaan yang terarah dan terkendali dengan baik. Sebuah tatanan kampus yang berkelanjutan menjadi sebuah usulan yang tepat guna dengan memasukkan tema-tema khusus dalam pengembangannya. Model tersebut merupakan masukan kepada Perguruan Tinggi dalam merencanakan komposisi tatanan massa bangunan dan site plan kawasan. Kawasan Agro Techno Park di Gresik Utara pada dasarnya merupakan sebuah kawasan dengan usulan tema yang menggabungkan antara industri dan kampus yang berlandaskan education dan research (Erica Campus). Dengan potensi yang kuat dan juga didukung oleh rencana infrastruktur pengembangan Gresik utara, maka kawasan ini sangat berpotensi untuk dikembangkan.. Hanyang University adalah salah satu contoh cluster Erica campus di Korea Selatan yang menerapkan standard baru dan diakui sebagai sekolah yang secara aktif bekerjasama dengan industri. Cluster ini harus memiliki kekhasan yang kuat dan spesifik karena berada pada kawasan agro industry sehingga dalam tatanan tapaknya selain tatanan massa, sirkulasi dan ruang luar terdapat kebutuhan-kebutuhan khusus yang perlu dikaji secara mendalam agar konsep pengabungan tercapai untuk mengembangkan arahan konseptual berupa model pengembangan kampus tematik.

\section{METODE PENELITIAN}

Model pengembangan kampus tematik ini akan didahului dengan penelitian yang komprehensif berkaitan dengan tema Agro Tekno Park dikawasan Gresik. Masalah penelitian yang muncul adalah aspek aspek apa saja yang perlu diperhatikan dalam penataan cluster tematik ini serta bagaimana kriteria yang membantu penguatan konsep-konsep perencanaan dan perancangan pengembangan kampus dalam jangka panjang. Menurut Eckbo [1] Perancangan tapak harus dipikirkan secara integratif dimana bangunan, konstruksi, ruang luar dan material direncanakan bersama 
Site Planning must be thought of as the organization of the total land area and space of the size for best use by the people will occupy it, This means an integrated concept in which building, engineering construction,open space and natural materials are planned together at one time

Dan menurut Simmonds [2] setiap tapak memiliki penggunaan yang ideal dan sebaliknya setiap penggunaan akan memili tapak yang ideal (For every site there is an ideal use, For every use there is an ideal site).

Menurut Simmonds ada 6 langkah dalam perencanaan dan perancangan arsitektur dan teknik yaitu seperti dalam Gambar 1 berikut:

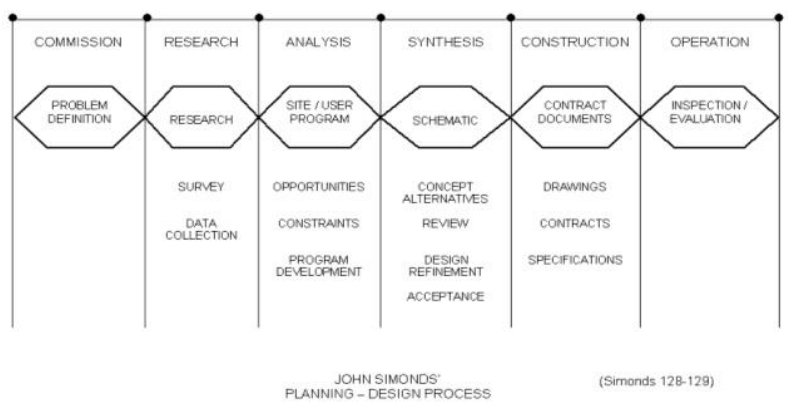

Gambar 1. Proses Perencanaan dan Perancangan

Herz [3] memberikan rekomendasi bahwa penataan kampus memerlukan perhatian pada hal hal antara lain:

a) Pengukuran miminum luasan termasuk halaman, parkir dan area hijau

b) Penyediaan multipurpose area yang dapat diperuntukkan berbagai kegiatan

c) Koordinasi dengan masterplan dan pemerintah setempat

d) Partisipasi dalam proses perencanan dengan stakeholder (pengajar, staf, mahasiswa, masyarakat komunitas, pemerintah dll)

e) Tim interdisipliner (pendidik, arsitek, arsitek lansekap, insinyur dan pemerintah lokalyang mengawal perencanaan tetapi tidak mendominasi

f) Kampus menjadi "learning tools itself"

Hal yang perlu diperhatikan dari bangunan riset [4] adalah sebagai berikut :

a) Mengambil manfaat dari elemen local yang signifikan

b) Ruang fungsional didalam yang bervariasi c) Memberikan perhatian pada elemen terbuka

d) Penggunaan Material baru dan hi tech

\section{HASIL DAN PEMBAHASAN}

Dalam Perancangan Tapak tiga hal yang penting adalah penataan massa, sirkulasi dan ruang luar [5]. Seperti layaknya kampus Erica, infrastruktur kampus dirancang untuk proses pembelajaran, penelitian, pengabdian kepada masyarakat dan bisnis dalam pengembangan 6 Fakultas dengan 12 program studi. Fakultas yang dibentuk adalah Fakultas Ekonomi dan Bisnis, Fakultas Sains dan Teknologi, Fakultas Kedokteran Hewan, Fakultas Kesehatan Masyarakat, Fakultas Perikanan dan kelautan, dan Fakultas Vokasi. Pengembangan yang akan dilakukan adalah dengan membuka 12 program studi dengan menerima 50 mahasiswa tiap program studi. Jumlah ini akan mengalami peningkatan sampai masing-masing program studi terakreditasi dan mampu menampung 200 mahasiswa tiap program studi. Program studi yang dikembangkan terdiri dari 4 program studi social sciences dan 8 program studi life sciences (exacta).

Fasilitas yang harus tersedia selama proses pembelajaran adalah ruang kuliah dan diskusi, laboratorium (wet dan dry laboratory), ruang pertemuan, auditorium, ruang aktivitas mahasiswa dan fasilitas kemahasiswaan, perpustakaan, asrama mahasiswa, stadion dan fasilitas penunjang aktivitas pembelajaran lainnya. Pendidikan vokasi pada dasarnya adalah sistem pendidikan tinggi yang diarahkan pada penguasaan keahlian terapan tertentu. Dengan demikian fasilitas pendidikan vokasi , tidak saja menyediakan ruang kelas teori tetapi juga dilengkapi dengan laboratoriumlaboratorium praktek yang lengkap dan spesifik untuk terapan bidang tertentu. Dalam konteks pendidikan terapan agrobisnis secara garis besar setidaknya terdapat 2 (dua) macam laboratorium yaitu :

a. Laboratorium dalam ruang

b. Laboratorium luar ruang (lahan, kebun, tambak, hutanpendidikan, kandang, pilot plant pengolahan,)

Asumsi yang digunakan untuk penetapan jenis tanaman agro terkait dengan fasilitasnya adalah:

a. Tanaman pangan

b. Tanaman industri 


\section{c. Tanaman keras}

Sedangkan untuk agro hewani yang digunakan adalah Perikanan.

Pengelompokan Sarana \& Prasarana

1. Kelompok Sarana dan Prasarana Akademik, terdiri atas:

1.1. Sarana dan Prasarana Akademik Umum:
a) Sarana dan prasarana kuliah,
b) Sarana dan prasarana perpustakaan,
c) Sarana teknologi informasi dan komunikasi (TIK),
d) Sarana dan prasarana dosen,
e) Sarana dan prasarana belajar mandiri
f) Sarana dan prasarana bersama

1.2 Sarana dan Prasarana Akademik Khusus:
a) Laboratorium (dalam ruang)
b) Studio,
c) Bengkel kerja,
d) Lahan praktik (laboratorium luar ruang)
e) Tempat praktik lainnya

2. Kelompok Sarana dan Prasarana Non Akademik, terdiri atas:

2.1. Sarana dan Prasarana Manajemen:

a) Sarana dan prasarana pimpinan,

b) Sarana dan prasarana tata usaha,

c) Sarana dan prasarana rapat,

d) Sarana dan prasarana penelitian dan pengabdian pada masyarakat (PPM),

e) Sarana dan prasarana penjaminan mutu.

2.2. Sarana dan Prasarana Penunjang:

a) Tempat beribadah,

b) Ruang konseling,

c) Ruang kesehatan,

d) Gudang,

e) Kantin,

f) Tempat parkir.

g) Lapangan/ Fasilitas Olah Raga

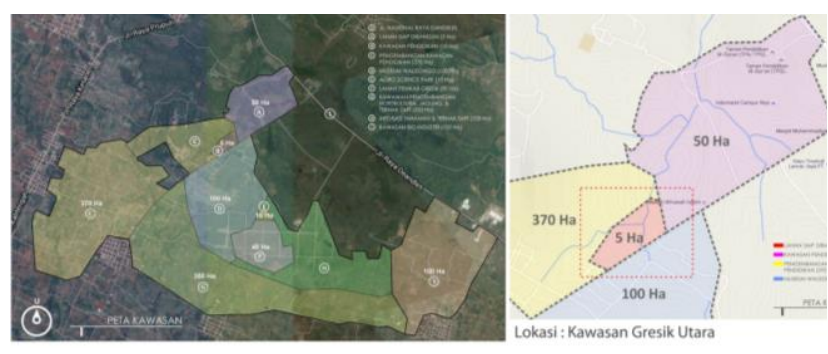

Gambar 2. Peta Kawasan Pengembangan

Tinjauan aspek tapak dan persyaratan fisik lokasi akan memperlihatkan adanya potensi pada lahan untuk menjadi pengembangan kampus tematik dalam hal ini kampus vokasi dengan konsep agrotekno park. Secara umum Gambar 2 merupakan Peta Kawasan Pengembangan.

\section{Aspek Tapak}

Lokasi yang akan dibangun menjadi kampus Agro Techno Park berada di wilayah kabupaten Gresik utara. Lokasi berada di wilayah quarry batu kapur dan berbatasan dengan lahan-lahan jalan arteri dan lahan kosong lainnya. Posisi lokasi ini relatif jauh dari kampus utama yang pusatnya berada di Surabaya, sehingga memang harus dilengkapi dengan sarana dan prasarana sesuai dengan standar untuk melayani semua program studi pada masing-masing lokasi kampus. Lahan yang akan dikembangkan menjadi kampus dalam kawasan Agro Techno Park ini berada di desa Siwalan, Kecamatan Panceng Kabupaten Gresik. Lokasi berada di tepi jalan Nasional Deandles menjadikan lokasi ini mudah diakses dari kota Gresik maupun dari kota Lamongan. Ditinjau dari aspek jarak antara lokasi pengembangan ke Kota Lamongan sekitar \pm 22,5 km dan dari kota Gresik sekitar $34 \mathrm{~km}$ maka pengembangan kawasan ini akan memberikan dampak positif bagi kemajuan masyarakat kabupaten Gresik namun juga memberikan "keuntungan" yang lebih luas ke masyarakat kabupaten Lamongan.

Bentuk lahan memanjang dari selatan kearah utara, sisi selatan lahan lebar \pm 120 meter dan \pm 300 meter di sisi utara yang berbatasan dengan jalan Deandels, panjang lahan \pm 1.500 meter. Ditinjau dari aspek bentuk, ukuran lahan dan posisi tapak maka akses masuk ke lahan ini yang paling menguntungkan apabila didekati dari arah utara atau dari jalan Deandels. Panjangnya tapak ini akan memberikan kemudahan bagi perancang tapak untuk menciptakan urutan potongan pemandangan yang berfariasi dan tidak membosankan.

\section{Aspek Kondisi Topografi}

Berdasarkan pengamatan diketahui bahwa kemiringan lahan (slope) sangat kecil (standard adalah < 15\%). Hal ini mengindikasikan kondisi lahan secara rata-rata merupakan lahan datar. Perbedaan elevasi yang signifikan hanya terjadi pada area tengah lahan yang mempunyai elevasi cukup rendah dari jalan. 
Pengamatan melalui peta rupa bumi yang diterbitkan oleh Badan Informasi Geospasial (BIG), yaitu titik tertinggi lahan +37 meter dpl dan titik terendah adalah +27 meter dpl, beda elevasi \pm 10 meter jadi lereng di permukaan lahan kurang lebih sebesar $1 \%$, relatif datar. Kemiringan tapak $1 \%$ ini merupakan potensi tapak dalam hal menyelesaikan sistem drainase. Jika dalam tapak terdapat bagian yang memiliki lereng lebih dar $20 \%$ maka diperlukan pekerjaan pemotongan dan pengurugan bahkan sampai diperlukan dengan perkuatan dinding penahan atau konstruksi turap. Dibagian tengah tapak secara topografis berupa lembah, hal ini akan berpotensi jika ditempat itu ditempatkan bak penampung air hujan.

\section{Aspek Jenis Tanah}

Jenis tanah secara keseluruhan adalah batu kapur dengan lapisan tanah liat di atasnya. Pada kondisi tanah demikian sebagian besar lahan tertutup oleh vegetasi jenis semak belukar dan ilalang.

\section{Aspek Potensi Penyimpanan Air}

Pada kenyataannya pada posisi kontur tanah terendah terdapat embung (reservoir air) dengan luasan yang relatif besar. Dengan pengaturan kedalaman air, maka embung ini sangat potensial sebagai penyedia air agrikultur dengan volume yang relatif besar. Pada sisi selatan dilalui saluran air yang pada saat musim kemarau tidak tampak air didalamnya, akan terisi air dimusim hujan. Diperlukan usaha lebih lanjut untuk memenuhi kebutuhan air bersih di area kampus dalam kawasan Agro Techno Park.

\section{Aspek Utilitas Kota}

Adanya jalan raya Daendles pada sisi utara lahan yang merupakan bagian dari jalan propinsi mengindikasikan bahwa infrastruktur kota seperti listrik dan air dapat di tapping (di sambungkan ke jaringan lahan) pada jalur tersebut. Hal ini sekaligus dapat menjamin bahwa pengembangan yang akan dilakukan pada lahan tersebut sangat memungkinkan tanpa perlu mengadakan pembangkit atau pengolah mandiri.

\section{Aspek Akses Lokasi}

Akses lokasi terutama dapat dicapai dari jalan raya Daendles sedangkan akses lain dapat dijangkau dari sisi timur, melalui jalan desa yang kelak dapat ditingkatkan kelas jalannya. Keberadaan jalan/ akses alternatif ini sekaligus menjawab keperluan adanya akses kondisi darurat.

\section{Aspek Zoning /Pembagian Area dalam Site Planning}

Dalam pembagian area dalam perencanaan tapak diperlukan perhitungan kepadatan. Kepadatan yang dimaksudkan adalah ratio antara luas lahan dibanding dengan koeffisien dasar bangunan. Kepadatan merupakan mekanisme untuk mengatur keleluasaan gerak, nilai privat dan kontak social penghuni. Saat ini standar yang sering dipakai untuk kepadatan suatu kawasan adalah 60\% dasar bangunan dan $40 \%$ ruang luar. Untuk memberikan keleluasaan gerak dan aktivitas kampus yang lebih baik disarankan agar kepadatan di lahan kampus dalam kawasan Agro Techno Park ini menggunakan kepadatan rendah, yaitu menerapkan Koeffisien Dasar Bangunan sebesar $40 \%$, dan ruang luar sebesar $60 \%$. Dimaksud dengan ruang luar adalah fasilitas tapak berupa ruang jalan, parkir, taman, kolam dan fasilitas lainnya yang tidak beratap.

Dengan berbagai analisis aspek yang telah dilakukan maka kriteria perancangan yang dapat diterapkan pada penataan massa dan lansekap (ruang luar) adalah sebagai berikut:

a) Berada di remote area, agar terhindar dari gangguan pencemaran air, pencemaran udara dan kebisingan.

b) Lahan relatif luas (dapat menampung sarana dan prasarana untuk melayaniseluruh kegiatan pembelajaran dalam perguruan tinggi tersebut)

c) Topography relatif datar/ tidak curam

d) Mempunyai bentang lahan yang memungkinkan untuk dikembangkan sebagai lahan laboratorium terbuka agro

e) Mempunyai potensi penampungan air hujan sebagai bagian dari penyediaan air agrikultur dalam volume relatif besar

f) Ketersediaan utilitas kota (air bersih, listrik)

g) Akses lokasi yang mudah dari jalan utama.

h) Harus ada fasilitas untuk penampungan air hujan yang cucup besar volumenya yang kemudian dilakukan penjernihan agar bisa dipakai sebagai air bersih dan juga untuk supply kebutuhan siram tanaman dan kolam ikan.

i) Harus ada sistem penyaluran air baku menggunakan pipa bertekanan yang ditanam di tanah dari embung sampai ke lokasi Kampus, 


\section{Konsep penataan tapak}

Kampus dalam kawasan Agro Techno Park ini dibagi menjadi 6 zonasi yang dapat dilihat pada Gambar 3, diantaranya :

1) Zona Bisnis

2) Zona Pemukiman

3) Zona Pendidikan

4) Zona Fasilitas Penunjang

5) Zona Laboratorium Luar

6) Zona Research Center

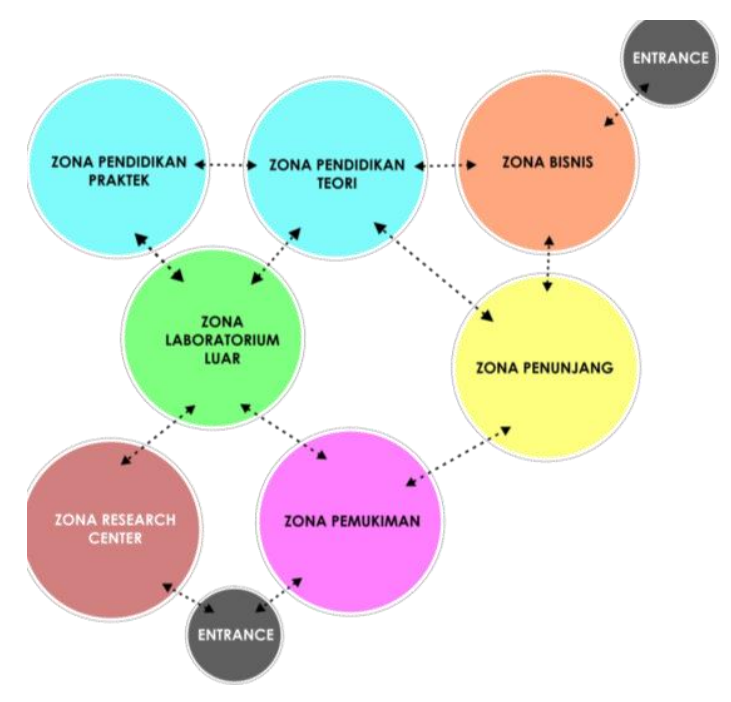

Gambar 3. Diagram Penataan Zona Kawasan

Pembagian dalam diagram diatas diterapkan pada tapak yang tersedia dapat menghasilkan tatanan yang dapat dilihat pada Gambar 4. Pada Gambar tersebut dapat dilihat pembagian warna yang menunjukan pembagian wilayah atau zonasi. Warna hijau pada peta tersebut menunjukan laboratirium luar yang merupakan kekhasan dari Agrotekno Park itu sendiri.

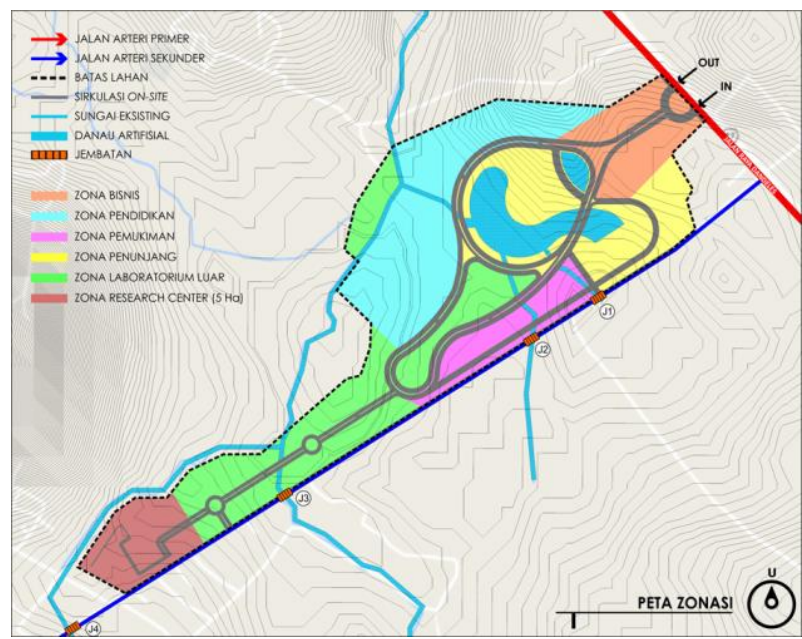

Gambar 4. Peta Zonasi

\section{Konsep Penataan Sirkulasi}

Secara umum, sistem sirkulasi merupakan sistem inner ring road yang digabung dengan kurvalinier. Penataan sirkulasi kendaraan dibagi menjadi 2 macam, yaitu jalur sirkulasi primer sebagai jalur utama dan Jalur sirkulasi sekunder sebagai jalur penghubung dari sub zona ke jalur utama.

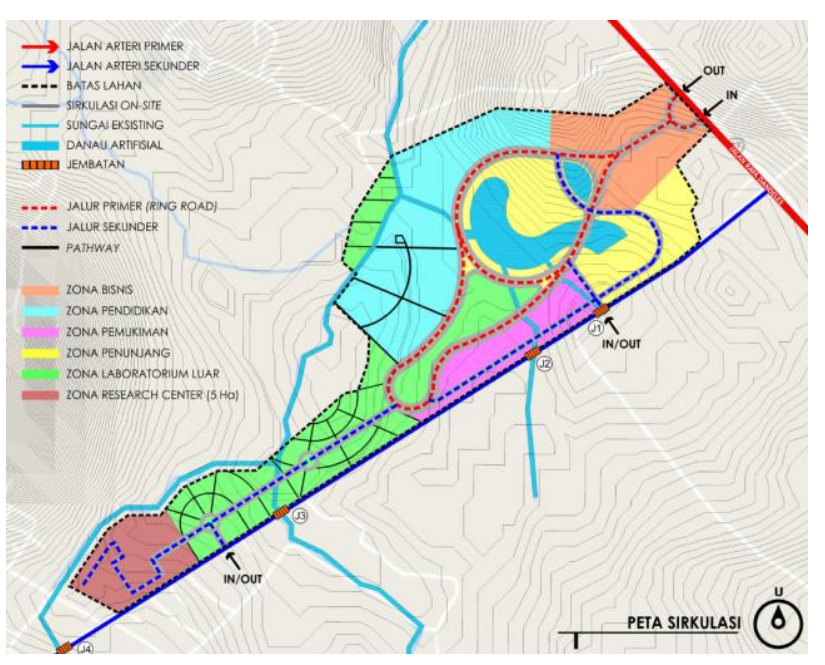

Gambar 5. Peta Sirkulasi

\section{Konsep Penataan Massa Bangunan}

Konsep penataan massa bangunan disebar menjadi beberapa cluster sesuai peruntukannya dapat dilihat pada Gambar 6 Area bisnis diletakkan di dekat entrance utama kawasan. Area permukiman diletakkan dekat dengan area bisnis. Area fasilitas penunjang diletakkan di bagian tengah kawasan, sedangkan area khusus pendidikan diletakkan di bagian tengah hingga belakang kawasan. Peletakkan orientasi wajah 
pada tiap massa bangunan didasarkan pada 2 hal yaitu keadaan site terhadap Jalan \& bangunan dan lingkungan sekitar

Bentuk Site kawasan Agro Techno Park yang cenderung berkontur pada beberapa titik menjadikan penataan berpengaruh pada orientasi massa bangunan. Didalam site, bangunan Gedung Serbaguna menempati titik tertinggi pada site, sedangkan bangunan Research Center menempati titik yang rendah. Namun jika dilihat dari entrance utama, bangunan Dekanat dan Perpustakaan Pusat akan terlihat mendominasi. Sedangkan jika dilihat dari entrance kedua, yang berada di bagian selatan site, bangunan Research Center yang terlihat lebih dominan.

Lingkungan di sekitar site adalah area permukiman penduduk dan area pertanian. Hal ini menjadikan bangunan dalam kawasan Agro Techno Park ini nantinya akan menjadi pusat dari segala aktivitas yang ada di sekitar kawasan. Keberadaannya yang menyatukan konsep pendidikan dan riset akan menjadi orientasi sebagai ikon pada kawasan tersebut.

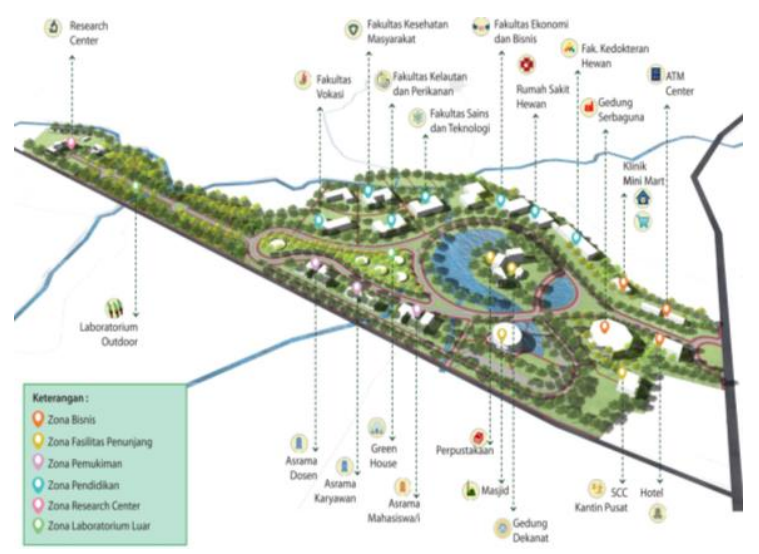

Gambar 6. Perspektif Mata Burung Model Pengembangan Kampus Tematik Agrotekno Park

\section{KESIMPULAN}

Pengembangan sebuah kampus dengan agrotekno park sebagai tema khusus memiliki beberapa ciri khas yang spesifik. Zona laboratorium luar menjadi pembeda dalam pengembangan kawasan. Zona ini merupakan area sharing laboratorium yang diperuntukkan sebagai penunjang pendidikan kampus Agro Techno Park, yang dapat berupa tempat pemeliharaan sumber daya alam baik berupa pembibitan tanaman ataupun pengembangbiakan ternak / kandang (lahan, kebun, tambak, hutan pendidikan, kandang, pilot plant pengolahan,). Dalam sebuah model pengembangan kampus tematik dalam kawasan agrotekno park tatanan massa bangunan dan lansekap kawasan perlu memperhatikan akan kebutuhan area tersebut.

\section{Daftar Pustaka}

Eckbo, G. (2009) Landscape for Living.

Simmonds, J.O. (2006) Landscape Architecture. New York: McGraw Hill Publishing.

Herz, M. (2012) Campus Landscape: Planning \& Design. Design Media Publishing Limited.

Appleton, N. (2013) Research Building: Planning \& Design. Design Media Publishing Limited.

Gunadi, S. (1989) Pedoman Perancangan Tapak \& Lingkungan. Surabaya : Utama Press 